\title{
Cigar advertising: targeting "baby-boomers" and older adults
}

In recent years, tobacco control advocates have focused increasing attention on the tobacco industry's targeting of cigarette advertisements to children and teenagers. Cigarette advertising and marketing have featured glamorous young movie and television stars, the Joe Camel cartoon character, Virginia Slims promotional items, and Marlboro "gear".

This increasingly targeted cigarette advertising has resulted in one group being largely overlooked by both tobacco control advocates and the tobacco industry: the older population. However, one increasingly popular tobacco product, the cigar, seems to have found its core market in the baby-boomer and older adult population. This older population constitutes a large and growing share of the consumer market. In 1990, 31.3 million Americans were aged 65 or older; in 1995, 33.5 million Americans (12.8\% of the total population) were aged 65 and older, an increase of $7 \%$ in only five years. ${ }^{12}$ Furthermore, the baby-boom generation (now between the ages of 32 and 51) constitutes approximately $30 \%$ of the population of the United States. ${ }^{3}$ By the year 2010, when

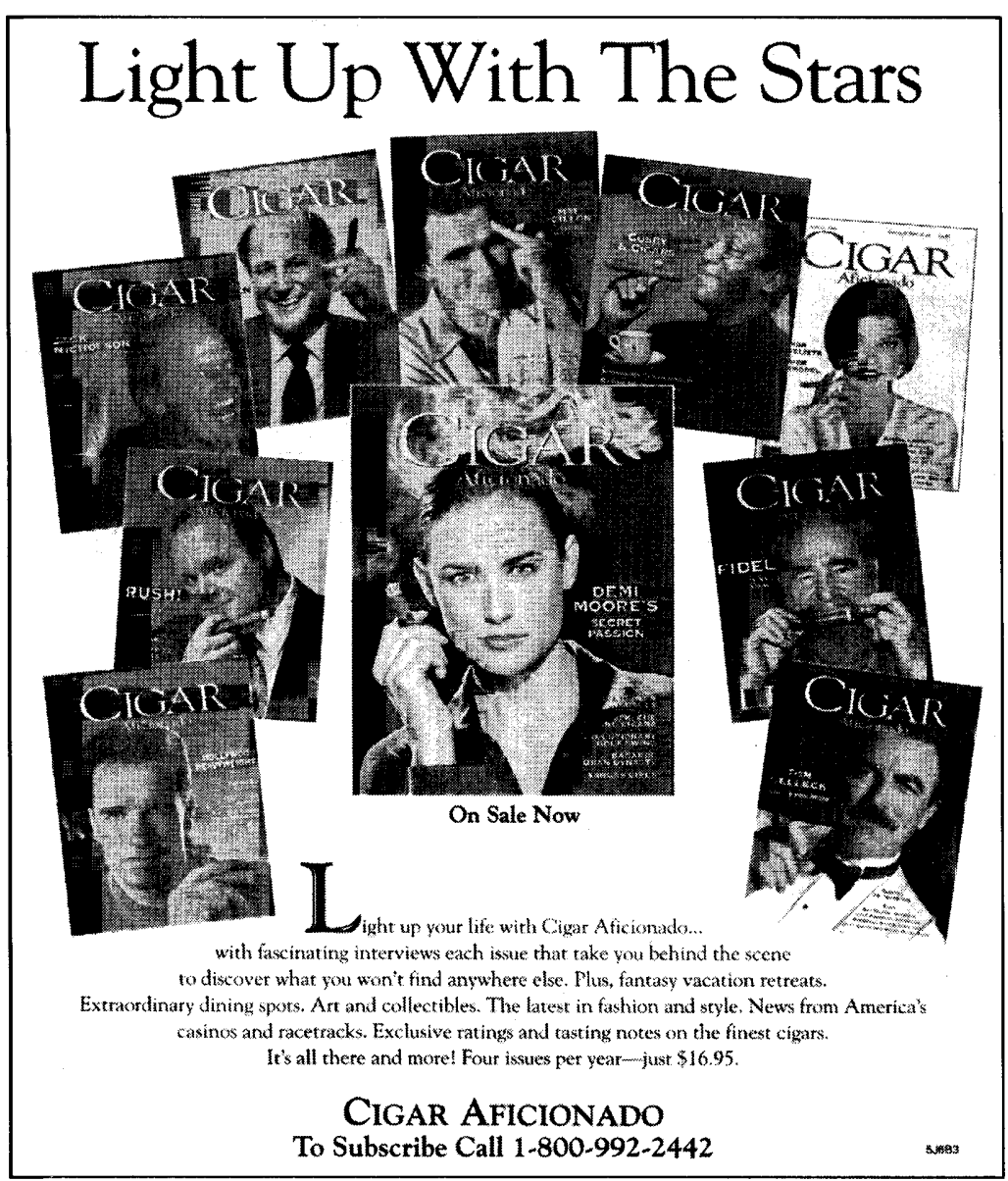

Figure 1 Covers of Cigar Aficionado often feature older movie stars. the baby-boom generation (born between $\frac{0}{8}$ 1946 and 1964) reaches age 65,40 million $\%$ Americans will be aged 65 and older, an almost $\overrightarrow{0}$ $20 \%$ increase in a 15 -year period. When all of $\overrightarrow{\vec{A}}$ the baby-boomers have reached age 65 , in $\vec{\omega}$ 2030 , more than $20 \%$ of the United States $\stackrel{?}{?}$ population will be 65 and older.

As young people, these baby-boomers and $\dot{\omega}$ older adults were primary targets of the $\overrightarrow{0}$ cigarette industry's marketing agenda, but they 음 are no longer. Because almost $90 \%$ of smokers begin smoking cigarettes by the age of $18,{ }^{4}$ and $\mathbb{C}$ as nicotine addiction is so difficult to $\frac{\mathbb{O}}{\mathbb{D}}$ overcome, the cigarette companies apparently $\frac{\mathbb{D}}{3}$ do not believe there is a need to spend ${ }_{\Phi}$ advertising dollars on the older population.

Unlike cigarette advertising with its $\vec{\theta}$ youth-focused advertisements using cartoon. characters and cowboy vistas, cigar advertising is largely found in publications geared towards older and more affluent adults: the New York Times Book Review, the daily and Sunday New $\frac{2}{\varnothing}$ York Times, the New Yorker Magazine and the $\stackrel{\unrhd}{\varrho}$ cigar industry's own magazines, Cigar $\overrightarrow{\overrightarrow{0}}$ Aficionado and Smoke. Cigar Aficionado-which 3 reached a circulation exceeding 225000 by the end of $1995^{5}$ - often features older, mature movie stars such as Jack Nicholson, Bill Cosby, 응 Danny DeVito, and Arnold Schwarzenegger as examples of those people who have achieved $\delta$ success and earned the right to smoke a cigar $\delta$ (figure 1).

Furthermore, cigars and their accompanying $\stackrel{\overline{0}}{\circ}$ products (humidors, cigar holders, lighters, $\frac{5}{3}$ etc.) are advertised in catalogues geared

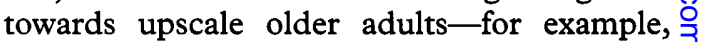
Brooks Brothers and For Counsel. These products, including the "Be a man-smoke 을 cigars" cufflinks offered by Brooks Brothers, $\frac{D}{0}$ promote cigars as symbols of prestige and success. ${ }^{6}$

Cigars are also expanding their presence in $N$ Hollywood. No longer banished to "mob mov- N్ ies," cigars surfaced in an advertisement for 0 The First Wives Club, showing the three female stars (all of baby-boomer age) holding cigars $\frac{\bar{D}}{\mathrm{D}}$ (figure 2). Furthermore, cigars continue to be a $\stackrel{\oplus}{+}$ popular prop in many major motion pictures $T$ including such recent films as Independence $\frac{\vec{D}}{\vec{D}}$ Day, The Associate, Ferry Maguire, and Wyatt $\stackrel{\bigcirc}{\odot}$ Earp.

In the first nine months of 1996, the cigar industry increased their advertising expendi- 8 tures by $438 \%{ }^{8}$ This recent growth in cigar응 advertising has been led by General Cigar's

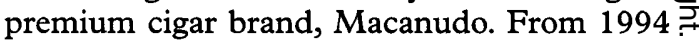
to 1995, Macanudo increased its advertising budget $193 \%$ to $\$ 1.45$ million. ${ }^{9}$ Its newest campaign highlights two men-one older and one younger-sharing cigars as a common 


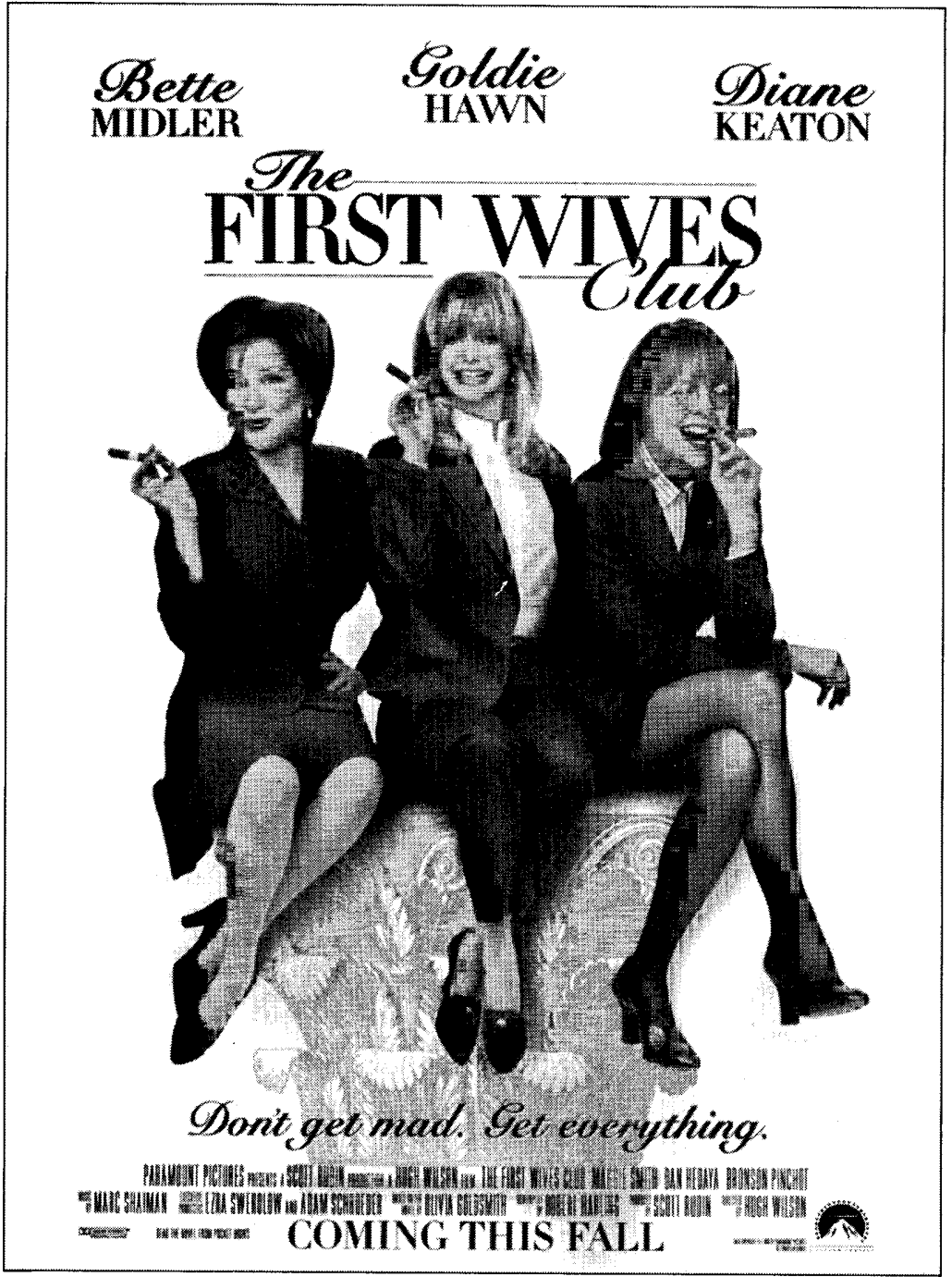

Figure 2 Three movie stars, all of baby-boomer age, holding cigars in an advertisement for The First Wives Club.

interest and a symbol of maturity and success (figure 3).

Although cigars and their growing popularity among 20,30 , and 40 year olds has now attracted attention, ${ }^{11}{ }^{11}$ their advertising and promotion have only recently begun to be challenged. This delayed response to the cigar

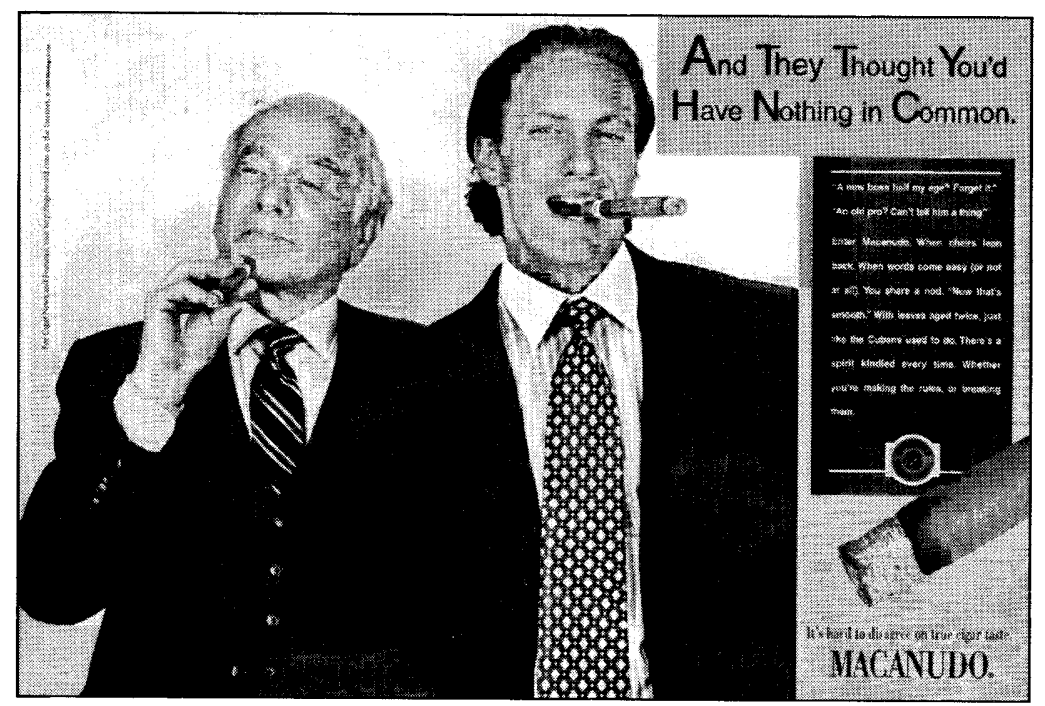

Figure 3 Two men-one older and one younger-sharing cigars in an advertisement for Macanudo, a premium brand.

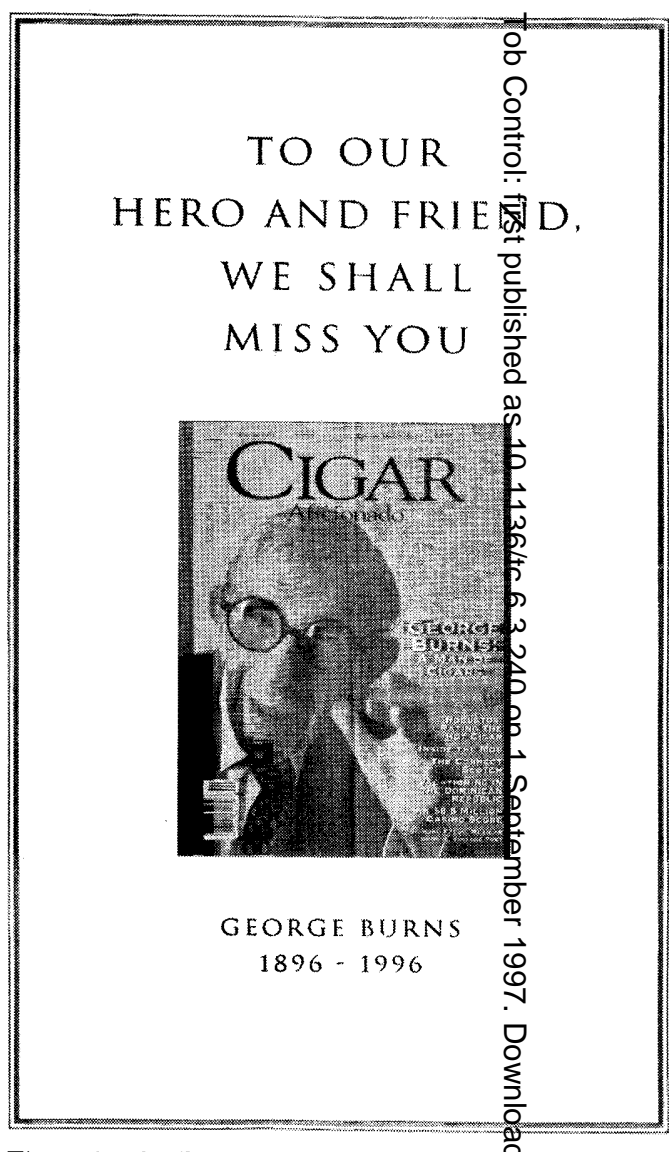

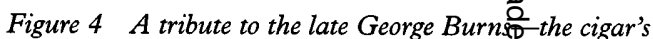
most popular "poster-child"-in Cigar Aficionado, which featured Burns on an earlier cover of the ma再zine.

industry's advertising surge appears to be the result of two factors: first, the cigar companies are not yet blatantly or explicitly ta然eting children; and second, cigars are notocommonly believed to have the same health effects as cigarettes. กุ

Although the health effects of cigar smoking have not been researched nearly $\stackrel{4}{a}$ much as those of cigarette smoking, cigar $\frac{5}{3}$ moking is known to cause cancer of the larynx, mouth, oesophagus, and lungs. ${ }^{12}$ Also linked to cigars is an increased likelihood (as compared with non-smokers) of developing chron 3 obstructive pulmonary disease, heart disease, and vascular disease. However, with George Burns as the cigar's most popular "poster-chald" (figure 4 ), the health dangers of cigar sfloking are subtly undercut.

స

After the US Surgeon General's first report on smoking and health in \$64, cigar consumption in the United State ${ }^{\circ}$ peaked at 9.1 billion. ${ }^{13}$ Whether or not there was a causal relationship between these two even is uncertain. However, there is much specillation that the increased awareness of the health consequences of cigarette smok黹g caused many adult cigarette smokers to switch to cigars, perceived as less risky to ong's health. ${ }^{13}$ Given the current environment regerding cigarette smoking and its health conseqüences, it is likely that the recent growth in ciga $\vec{F}^{+}$consumption in the United States is similar to the phenomenon in the mid-1960s. In 1993 cigar consumption in the United States hit an all-time low of 2.1 billion cigars. ${ }^{10}$ Since then, annual 
sales for premium cigars have increased $50 \%$ or more. ${ }^{13}$ According to the Cigar Association of America, more than 10 million people currently smoke cigars, up from six to eight million five years ago. ${ }^{11}$

Data from the 1992 National Health Interview Survey show that $24.7 \%$ of those 55-64 years old and $21.1 \%$ of those over 65 years of age have smoked a cigar during their lifetime. Furthermore, among those who have ever smoked cigars, $58.2 \%$ of those aged 55-64 years and $57 \%$ of those 65 years of age and older have smoked 50 or more cigars in their lifetime. ${ }^{14}$

In addition to the perceived low health risks of cigar smoking, cigars promote an aura of glamour, prestige, and success. Dinner parties for cigar smokers only, private cigar clubs, and cigar bars all add to the perception that cigar smoking is for the elite. ${ }^{13}{ }^{15}$ These marketing practices demonstrate that cigar advertising is targeted to an older population who can afford the price of a "good cigar".

The combination of targeted cigar advertising to middle-aged baby boomers and older adults, the aura of glamour and prestige surrounding cigar smoking, and the perceived "safe substitution" of cigars for cigarettes pose a new tobacco danger. It is important that this growing cigar fad, and its inherent health dangers, not be overshadowed by the cigarette battles currently being fought in the tobacco war.
JUDITH L FALIT -1

The Center for Social Gerontology, Inc. 음 2307 Shelby Avenue, Ann Arbor, Michigan 48103, USA;응 email:tcsg@izzy.net

1 US Senate Special Committee on Aging, American Association of Retired Persons, Federal Council on Aging, and Administration on Aging. Aging America: trends and projections. (DHHS Publication No (FCoA) 91-28001.) Washington, DC: Department of Health and Human $\frac{\bar{\sigma}}{\bar{G}}$ Services, 1991:2.

2 American Association of Retired Persons and Administration on Aging. A profile of older Americans. Washington DC: American Association of Retired Persons, 1996.

3 US Bureau of the Census. Population projections of the United States by age, sex, race, and Hispanic origin: 1995 to $2050 .-$ Washington, DC: US Bureau of the Census, Current Population Reports, 1996:25-1130.

4 Robert Wood Johnson Foundation. Youth access to tobacco. $\vec{\omega}$ Princeton, New Jersey: Robert Wood Johnson Foundation, 1995.

5 Donaton $S$. Where there's smoke, there's Shanken's star. \% 'Cigar Aficionado' thumbs nose at the politically correct $\omega$ world. Advertising Age 1996 Mar 22 (suppl):S2.

6 Brooks Brothers Clothiers. 1996 Holiday catalogue, page 4 . N American Lung Association. Thumbs up! Thumbs down! 1996. <http://www.lungusa.org/hollywood/trends.html>

8 Maxwell J. Cigar craze continues. Tobacco Reporter 1997 Jun:28.

$9<$ http://adage.com/news and features/special reports/ $\mathcal{D}$ mktg100-1996/96-100.08.html>

10 Marriott M. Paying for the privilege of puffing in peace. New York Times 1995 fov $20 . \mathrm{B} 1$.

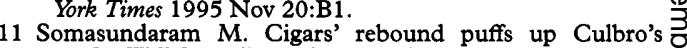
profit. Wall Street fournal 1996 Feb 16 .

12 Henningfield JE, Hariharan M, Kozlowski LT. Nicotine content and health risks of cigars. $\Im A M A 1996 ; 276: 1857-\vec{G}$ 8

13 Brody JE. Personal health. New York Times 1996 May 29:B9. .

14 Gerlach KK, Cummings KM. Trends in cigar consumption and smoking prevalence. In: Cigar smoking in the United States. Health effects and trends. Bethesda, Maryland. National Cancer Institute monograph, 1997. In press.

15 Poundstone P. Choking on hype. Mother fones 1996 Mar/Apr. 